NASA/TM-2005-213594

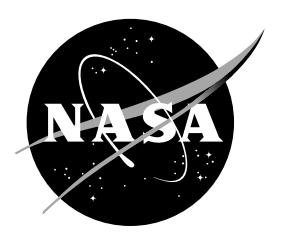

\title{
Processing of Signals From Fiber Bragg Gratings Using Unbalanced Interferometers
}

Grigory Adamovsky and Jeff Juergens Glenn Research Center, Cleveland, Ohio

Bertram Floyd

Akima Corporation, Fairview Park, Ohio 
Since its founding, NASA has been dedicated to the advancement of aeronautics and space science. The NASA Scientific and Technical Information (STI) Program Office plays a key part in helping NASA maintain this important role.

The NASA STI Program Office is operated by Langley Research Center, the Lead Center for NASA's scientific and technical information. The NASA STI Program Office provides access to the NASA STI Database, the largest collection of aeronautical and space science STI in the world. The Program Office is also NASA's institutional mechanism for disseminating the results of its research and development activities. These results are published by NASA in the NASA STI Report Series, which includes the following report types:

- $\quad$ TECHNICAL PUBLICATION. Reports of completed research or a major significant phase of research that present the results of NASA programs and include extensive data or theoretical analysis. Includes compilations of significant scientific and technical data and information deemed to be of continuing reference value. NASA's counterpart of peerreviewed formal professional papers but has less stringent limitations on manuscript length and extent of graphic presentations.

- TECHNICAL MEMORANDUM. Scientific and technical findings that are preliminary or of specialized interest, e.g., quick release reports, working papers, and bibliographies that contain minimal annotation. Does not contain extensive analysis.

- CONTRACTOR REPORT. Scientific and technical findings by NASA-sponsored contractors and grantees.
- CONFERENCE PUBLICATION. Collected papers from scientific and technical conferences, symposia, seminars, or other meetings sponsored or cosponsored by NASA.

- SPECIAL PUBLICATION. Scientific, technical, or historical information from NASA programs, projects, and missions, often concerned with subjects having substantial public interest.

- TECHNICAL TRANSLATION. Englishlanguage translations of foreign scientific and technical material pertinent to NASA's mission.

Specialized services that complement the STI Program Office's diverse offerings include creating custom thesauri, building customized databases, organizing and publishing research results ... even providing videos.

For more information about the NASA STI Program Office, see the following:

- Access the NASA STI Program Home Page at http://www.sti.nasa.gov

- E-mail your question via the Internet to help@sti.nasa.gov

- Fax your question to the NASA Access Help Desk at 301-621-0134

- Telephone the NASA Access Help Desk at 301-621-0390

- Write to:

NASA Access Help Desk

NASA Center for AeroSpace Information 7121 Standard Drive

Hanover, MD 21076 
NASA/TM-2005-213594



\section{Processing of Signals From Fiber Bragg Gratings Using Unbalanced Interferometers}

Grigory Adamovsky and Jeff Juergens Glenn Research Center, Cleveland, Ohio

Bertram Floyd

Akima Corporation, Fairview Park, Ohio

Prepared for the

International Symposia on Smart Structures and Materials/NDE sponsored by The International Society for Optical Engineering San Diego, California, March 7-10, 2005

National Aeronautics and Space Administration

Glenn Research Center 


\section{Acknowledgments}

The authors want to express their gratitude to Dr. Suwat Thaniyavarn, Founder, President, and CEO of EOSPACE, Inc., for helpful information and discussions on the design and operation of the polarization based $\mathrm{LiNbO}_{3}$ interferometer. This work was sponsored by the Alternate Fuel Foundation Technologies Sub-Project of the Low Emissions Alternative Power (LEAP) Project at the NASA Glenn Research Center.

This work was sponsored by the Low Emissions Alternative

Power Project of the Vehicle Systems Program at the NASA Glenn Research Center.

NASA Center for Aerospace Information 7121 Standard Drive

Hanover, MD 21076
National Technical Information Service 5285 Port Royal Road Springfield, VA 22100 


\title{
Processing of signals from fiber Bragg gratings using unbalanced interferometers
}

\author{
Grigory Adamovsky ${ }^{* a}$, Jeff Juergens ${ }^{\mathrm{a}}$, Bertram Floyd ${ }^{\mathrm{b}}$ \\ ${ }^{a}$ National Aeronautics and Space Administration, Glenn Research Center at Lewis Field \\ 21000 Brookpark Road, Cleveland, OH, USA 44135 \\ ${ }^{\mathrm{b}}$ AKIMA Corporation, Cleveland, OH, USA 44135
}

\begin{abstract}
Fiber Bragg gratings (FBG) have become preferred sensory structures in fiber optic sensing system. High sensitivity, embedability, and multiplexing capabilities make FBGs superior to other sensor configurations. The main feature of FBGs is that they respond in the wavelength domain with the wavelength of the returned signal as the indicator of the measured parameter. The wavelength is then converted to optical intensity by a photodetector to detect corresponding changes in intensity. This wavelength-to-intensity conversion is a crucial part in any FBG-based sensing system. Among the various types of wavelength-to-intensity converters, unbalanced interferometers are especially attractive because of their small weight and volume, lack of moving parts, easy integration, and good stability.
\end{abstract}

In this paper we investigate the applicability of unbalanced interferometers to analyze signals reflected from Bragg gratings. Analytical and experimental data are presented.

Keywords: Fiber Bragg gratings, temperature sensors, fiber optics, interferometer

\section{INTRODUCTION}

Fiber Bragg gratings (FBGs) have found numerous applications in sensing and communication systems. ${ }^{1}$ The principle of FBGs is based on a selective spectral reflectivity of a section of fiber that has a periodically varied refractive index. The period of these variations is affected by the environmental conditions the fiber is in and varies with changes in the environment. Thus, with changes in the environment, the spectra of the reflected signal changes. This property makes an FBG a superior sensing element.

Another distinguished feature of Bragg grating sensors is that these sensors are so called spectral sensors. This means that the response of Bragg gratings to changes in the environment occurs in the spectral domain. The position of the signal peak in the spectral domain is affected by the environment (temperature, pressure, etc.). To evaluate the performance of an FBG one should send a signal reflected from the grating to a spectrometer with a dispersive element like spectral prism or focal plane array detector. Sophisticated software then would correlate a position of the optical spot on the array detector with the wavelength of light that generated the spot. Such an arrangement suffers drawbacks because of the weight and size of constituent components. Another approach, more practical and suitable for aerospace applications, would involve a smaller and lighter device capable of converting the wavelength to intensity. One of such devices is an unbalanced interferometer. ${ }^{2-4}$

*Grigory.Adamovsky-1@ nasa.gov; 216-433-3736 


\section{UNBALANCED INTERFEROMETER}

\subsection{Interference in unbalanced interferometer}

It has been previously shown that the intensity pattern resulting from the interference of two optical beams having identical intensities, $I_{0}$, and wavelengths, $\lambda_{0}$, has the following form:

$$
I=2 I_{0}\left[1+\cos \left(\frac{2 \pi}{\lambda_{0}} \Delta(n L)\right) \gamma\right],
$$

where $I_{0}$ is the light intensity in each arms of the interferometer,

$\lambda_{0}$ is the central wavelength of the light,

$\Delta(n L)$ is the optical path difference or imbalance in the interferometer,

$\gamma$ is the fringe visibility function.

The optical path difference, $\Delta(n L)$, is a function of the physical lengths of the interferometer arms and the refractive indices of the arm materials. Changes in the environment may affect both the refractive indices and the physical length of the arms, altering the optical path length. The optical path difference of the two arms is called imbalance. The interferometer is also sensitive to the wavelength of light that passes through it. In this case, if the imbalance of the interferometer is unchanged, it becomes a wavelength detector.

The fringe visibility function is

$$
\gamma=\exp \left[-\left(\frac{\pi}{2 \sqrt{\ln 2}} \frac{\Delta \lambda}{\lambda_{0}^{2}} \Delta(n L)\right)^{2}\right]
$$

where $\Delta \lambda$ is the optical bandwidth.

Analysis of Eq. (1) show that continuous monotonic variations in the wavelength, $\lambda_{0}$, lead to quasi-periodic variations in the resultant intensity output of the interferometer.

\subsection{Instrument function}

The ability of an instrument to change the otherwise continuously constant spectrum of incident light is described by its instrument function. In the case of an unbalanced interferometer, its instrument function, as a function of wavelength, is described as follows:

$$
I(\lambda)=2\left[1+\cos \left(\frac{2 \pi}{\lambda} \Delta(n L)\right)\right]
$$

Figure 1 shows a plot of the computed instrument function of an unbalanced interferometer with an optical imbalance of $2.0 \mathrm{~mm}$. Oscillations in the wavelength domain are clearly observed and the period of these oscillations, $\Lambda_{\lambda}$, is approximately:

$$
\Lambda_{\lambda} \approx \frac{\lambda_{0}^{2}}{\Delta(n L)}
$$




\subsection{Observation of the instrument function}

To obtain an instrument function of an unbalanced interferometer, its input should be a time-domain Delta function, which in the spectral domain, corresponds to an infinitely broad spectrum. In practice we generate a quasi-transfer function by applying an input signal with a broad, but wavelength limited spectrum. Experimentally, the quasi-transfer function of the interferometer in the optical domain is obtained by sending broadband light through the interferometer and detecting the transmitted spectrum using a commercial optical spectrum analyzer. The source of the broadband light used in this experiment was a superluminescent light emitting diode with a nominal center wavelength of $1550 \mathrm{~nm}$ and optical bandwidth of $40 \mathrm{~nm}$. Figure 2 depicts the quasi-transfer function of the unbalanced interferometer used in the experiment. This plot clearly displays quasi-periodic changes of the resultant light intensity in the spectral domain and monotonic variations in the instrument function between its neighboring maximum and minimum values.

When an unbalanced interferometer is used to measure wavelength, the interferometer's instrument function causes its resultant light intensity to vary depending on the spectral position of the wavelength relative to the instrument function. If the wavelength of the incident light varies between the neighboring maximum and minimum values of the instrument function, then the value of the resultant light intensity changes monotonically.

\section{EXPERIMENT}

\subsection{Test setup}

The test setup, as seen in Fig. 3, consists of a thermally stabilized super-luminescent diode (SLED) light source connected to a $90 / 10$ coupler. The $10 \%$ output of the coupler is connected to a photodetector, PD, used to monitor the SLED stability throughout the experiment. The $90 \%$ output port of the coupler is connected to the first port of a 3-port fiber optic circulator. The second port of the circulator is connected to the FBG which is inside a box furnace. The reflected signal from the FBG propagates back through the circulator to an optical amplifier. The amplifier boosts the signal to a more easily detectable level. The amplified signal from the FBG is then multiplied by the instrument function of the unbalanced interferometer. The output of the interferometer is monitored using an optical spectrum analyzer (OSA). All equipment control and data acquisition is accomplished using LabVIEW. The arrangement permits recording and processing the quasi-instantaneous light spectra that reach the OSA as well as conducting a fast integration of the light intensities over a broad range of wavelengths. The integration of light intensities over a broad range of wavelengths is similar to a having a photodetector instead of the OSA.

The experiment consists of heating the furnace with the FBG from room temperature up to $500{ }^{\circ} \mathrm{C}$ and measuring the total power of the optical signal reflected by the FBG using the OSA. Because the optical signal, prior to reaching the OSA, has to pass through the unbalanced interferometer, its intensity is modulated by the interferometer's instrument function. Integrating the signals from the OSA during the heating process of the FBG provides information on changes in the total optical power and thus changes in the FBG's wavelength.

\subsection{Fiber Bragg gratings}

Conversion of wavelength to intensity assumes that the intensity of the optical signal reflected back from the FBG remains constant over a large range of temperatures. To assure the FBGs are stable, they to be specially treated. This treatment consists of annealing the gratings at $1000{ }^{\circ} \mathrm{C}$ for several hundred hours. This treatment leads to the dissipation of the original FBG and subsequent formation of secondary gratings in place of the original. It has been recently demonstrated that the secondary gratings exhibit high thermal stability, thus providing a stable intensity level to the interferometer. ${ }^{5-7}$

After evaluating the performance of the unbalanced interferometer, the FBG's response to changes in temperature was reevaluated by processing spectra of corresponding signals reflected by the grating. The setup for this was identical to the one described in Fig. 3 with the exception of the removal of the unbalanced interferometer from the setup. Figure 4 shows FBG spectra from this evaluation recorded at three different temperatures with a $100{ }^{\circ} \mathrm{C}$ interval. It can be seen in this figure that the peak power at the FBG reflected wavelengths was practically unchanged. 


\subsection{Unbalanced interferometer}

To keep the optical path difference of the interferometer constant, its construction takes advantage of the birefringent properties of a $\mathrm{LiNbO}_{3}$ crystal. Detailed descriptions of devices that utilize these properties and their principle of operation are described elsewhere. ${ }^{\mathbf{8 , 9}}$ The imbalance, $\Delta(n L)$, in the $\mathrm{LiNbO}_{3}$ crystals is generated by a difference in the transit time between the two orthogonally polarized components of light propagating through the crystal. These components have different refractive indices, $n_{o}$ and $n_{e}$, and are referred to as ordinary and extraordinary beams. The difference in the transit time for these two components leads to the optical imbalance.

The unbalanced interferometer was made from a long Z-cut $\mathrm{LiNbO}_{3}$ crystal that is approximately $20.05 \mathrm{~mm}$ long. This crystal splits the incident light into two orthogonally polarized components, which, after passing through the entire length of the crystal, accumulate the optical path difference. ${ }^{10}$ The refractive indices, $n_{o}$ and $n_{e}$, of the crystal follow the dispersion relationship for liquids and solids described by Sellmeier's dispersion formula. ${ }^{\mathbf{1 1}, \mathbf{2}}$ For a wavelength around $1550 \mathrm{~nm}$ at room temperature, the indices are found to be approximately $n_{o} \sim 2.211$ and $n_{e} \sim 2.138$. ${ }^{\mathbf{1 3}}$ Thus, over the length of the crystal, the accumulated optical path difference $L\left(n_{o}-n_{e}\right)$ is approximately $1.464 \mathrm{~mm}$.

Figure 5 shows the impact of the unbalanced interferometer on the FBG spectrum as observed by the OSA. The spectra were taken under conditions similar to those used for generating Fig. 4. Differences in the FBG peak power at the three temperatures shown are due to the unbalanced interferometer.

\section{RESULTS AND DISCUSSION}

The results of this work have demonstrated that an unbalanced interferometer can change the peak power of an FBG's spectrum. When the FBG's reflected wavelength moves in the spectral domain according to an applied temperature, that change in wavelength can be converted into a corresponding change in the intensity. To track a temperature unambiguously, the interferometer should be constructed in such a way as to make the conversion monotonous. In other words, the period of the quasi-periodic instrument function and the range of thermal variations should match such that changes in the temperature applied to the FBG would always place the corresponding FBG reflected wavelength at either leading or trailing slopes of the instrument function. Figure 6 shows four FBG spectra obtained at different temperatures that place the corresponding FBG wavelengths on a leading slope of the instrument function of the interferometer. Those spectra integrated over a broad range of wavelengths are depicted in Fig. 7. This figure shows the increase in total power as a function of temperature over a range from ambient to about $130^{\circ} \mathrm{C}$.

As shown in previous work, the peak wavelength of an FBG is an accurate representation of temperature and, after annealing, its power output is very stable over a wide temperature range. Also, the power output of the interferometer followed the product of its instrument function and the FBGs input signal very precisely. However an accurate correlation between temperature and the interferometer's output was hampered by the instability of the interferometer. The interferometer was sensitive to the input light's polarization state which we did not have a good means of controlling in this work. With better control of the input polarization, the signal from interferometer would have most likely have been more stable. Alternately, using a depolarizer at the input to the interferometer should greatly reduce interferometer's sensitivity to polarization state. The interferometer used would, in practice, only allow for a relatively narrow temperature range for the sensor. Using an interferometer with a shorter path would allow for a much broader temperature range. Given the results from this experiment, we believe that an FBG in combination with an unbalanced interferometer could be used as a compact temperature measurement system with a wide dynamic range. 


\section{REFERENCES}

1. Fiber Optic Smart Structures, Eric Udd, Ed., John Wiley \& Sons, Inc., New York, 1996.

2. Adamovsky, G., Lekki, J., and Lock, J.A., "Detection sensitivity optimization of optical signals generated by fiber optic Bragg gratings under dynamic excitation," Opt. Eng. 42(2), pp.425-430, 2003.

3. Kersey, A.D., Berkoff, T.A., and Morrey, W.W., "High-resolution fibre-grating based strain sensor with interferometric wavelength-shift detection," Electronics Letters 28 (3), pp. 236-238, 1992.

4. Kersey, A.D., Berkoff, T.A., and Morrey, W.W., "High-resolution fibre-grating based strain sensor with interferometric wavelength-shift detection," Electronics Letters 28 (3), pp. 236-238, 1992.

5. Juergens, J., Adamovsky, G., Bhatt, R., and Floyd, B., "Thermal Evaluation of Fiber Bragg Gratings at Extreme Temperatures," $43^{\text {rd }}$ AIAA Aerospace Science Meeting and Exhibit, Reno, NV, Jan. 2005, Paper\# AIAA-2005-1214.

6. Fokine, M., "Thermal stability of oxygen-modulated chemical composition gratings in standard telecommunication fiber," Opt. Lett., Vol. 29, pp. 1185-1187, 2004.

7. Grubsky, V., Starodubov, and Morey, W.W., "High-temperature Bragg gratings in germanosilicate fibers," in Technical Digest, The Bragg Gratings Photosensitivity and Poling in Glass Waveguides, OSA Topical Meeting, September 1-3, 2003, Monterey, CA, Paper \# MB5.

8. Thaniyavarn, S.: "Optical modulation: Electro-optical devices," in Fiber and Electro-Optical Components (Handbook of microwave and optical components; v. 4, pp.168-198), Kai Chang, editor, John Wiley \& Sons, New York, 1991.

9. Tamir, T.: Guided-Wave Optoelectronics, $2^{\text {nd }}$ Edition, Springer-Verlag, Brooklyn, New York, 1990.

10. Thaniyavarn, S., EOSPACE Inc., private communications.

11. Born, M. and Wolf, E.: Principles of Optics, $6^{\text {th }}$ Edition, Pergamon Press, New York, 1980.

12. www.st-andrews.ac.uk/ wsquad/background/optics/opticst.htm

13. www.mtixtl.com/index.asp?PageAction=VIEWPROD\&ProdID $=116$

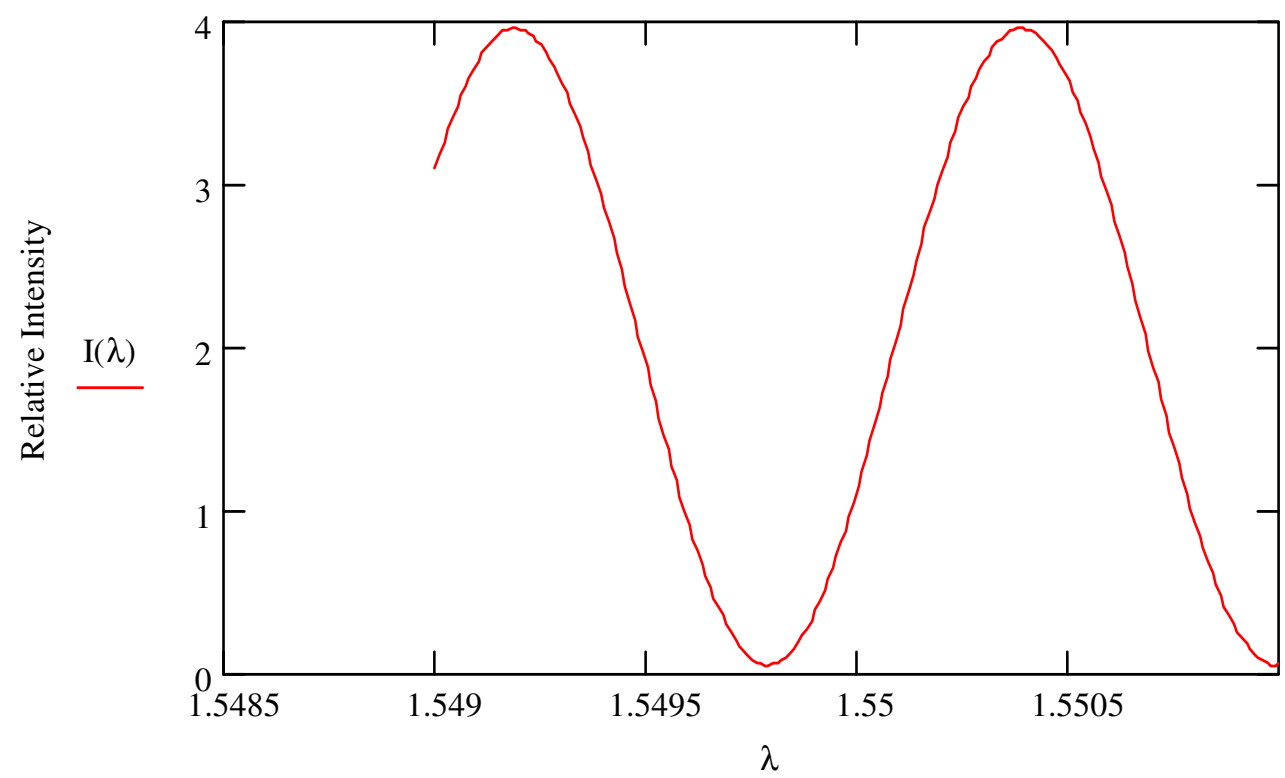

Wavelength, mkm

Fig. 1. Instrument function of an unbalanced interferometer with an optical imbalance of $2.0 \mathrm{~mm}$. 


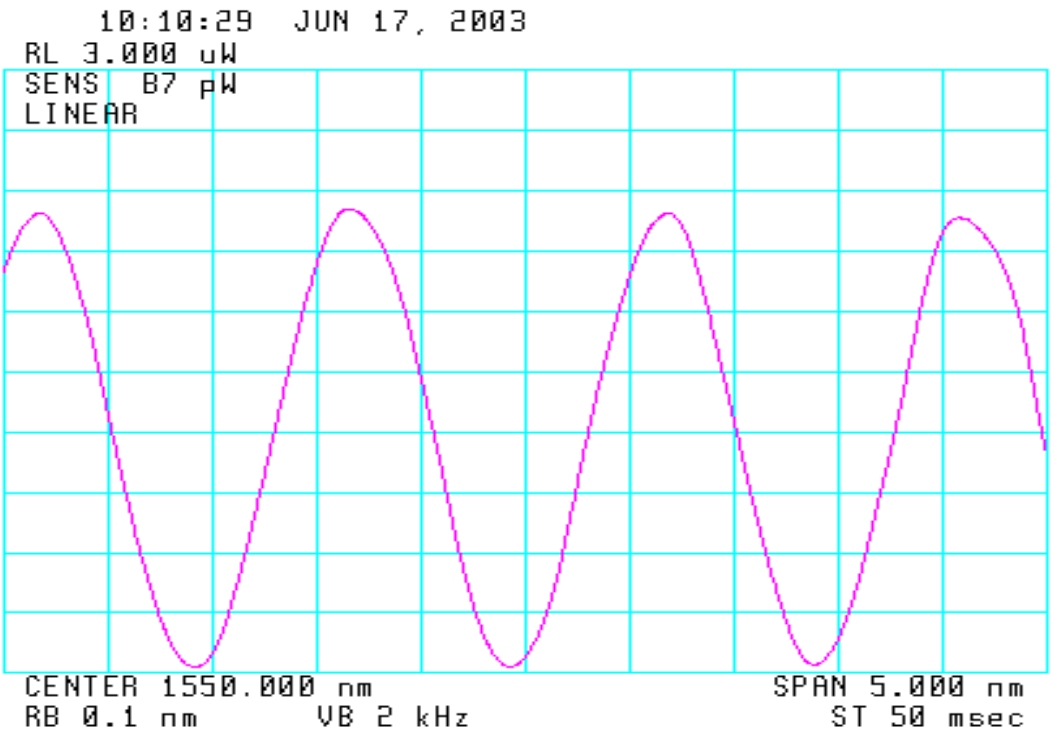

Fig. 2. Instrument function of an unbalanced interferometer observed on the screen of a spectrum analyzer.

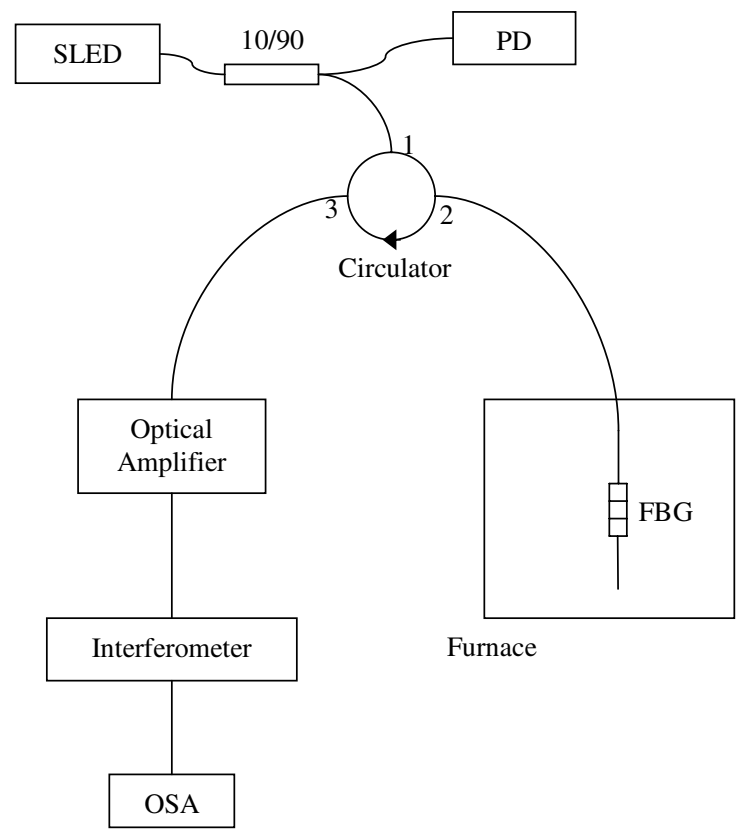

Fig. 3. Experimental setup to demonstrate the suitability of unbalanced interferometers for the wavelength-to-intensity conversion of signals generated by FBGs. 


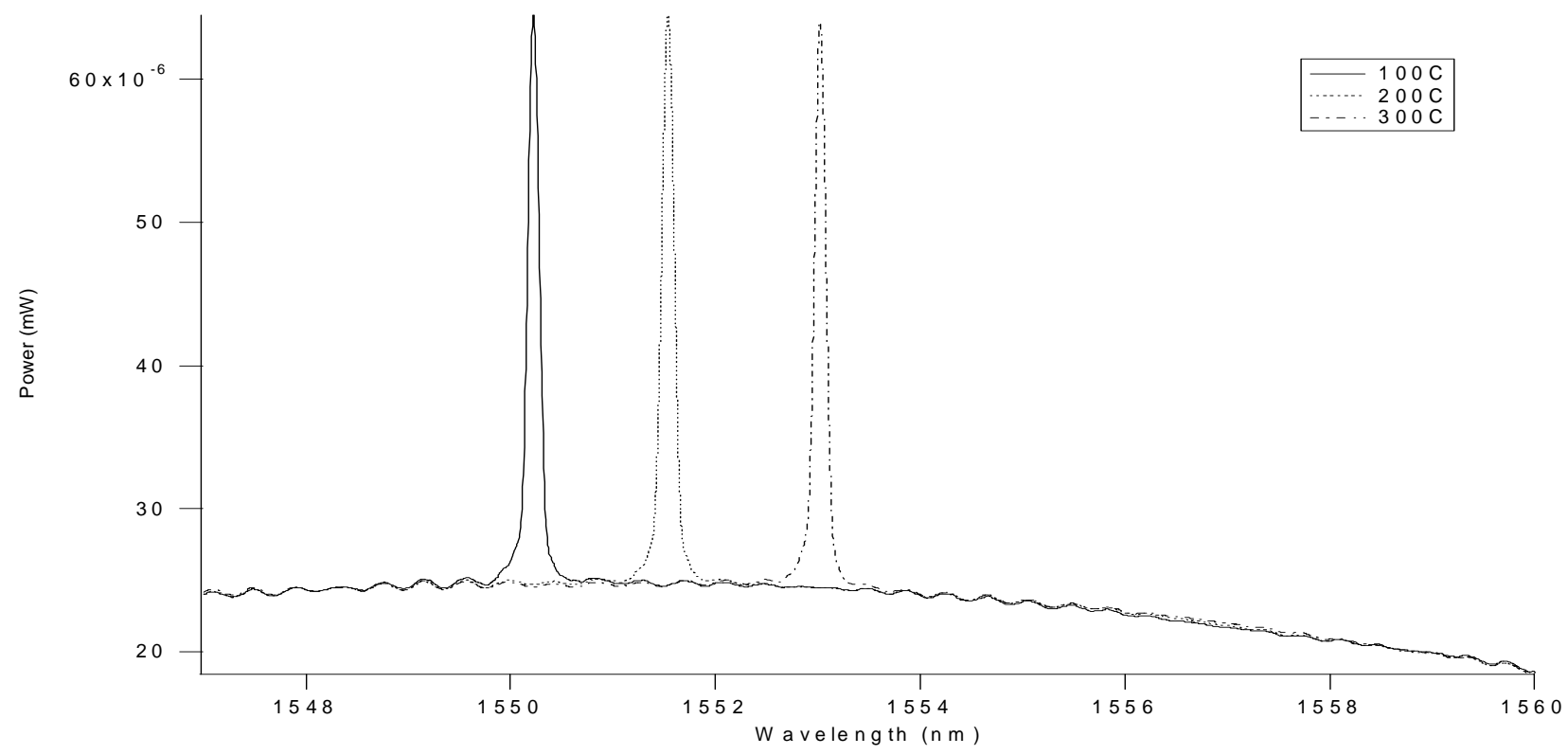

Fig. 4. FBG spectra recorded by a spectrum analyzer at three different temperatures with $100{ }^{\circ} \mathrm{C}$ intervals.

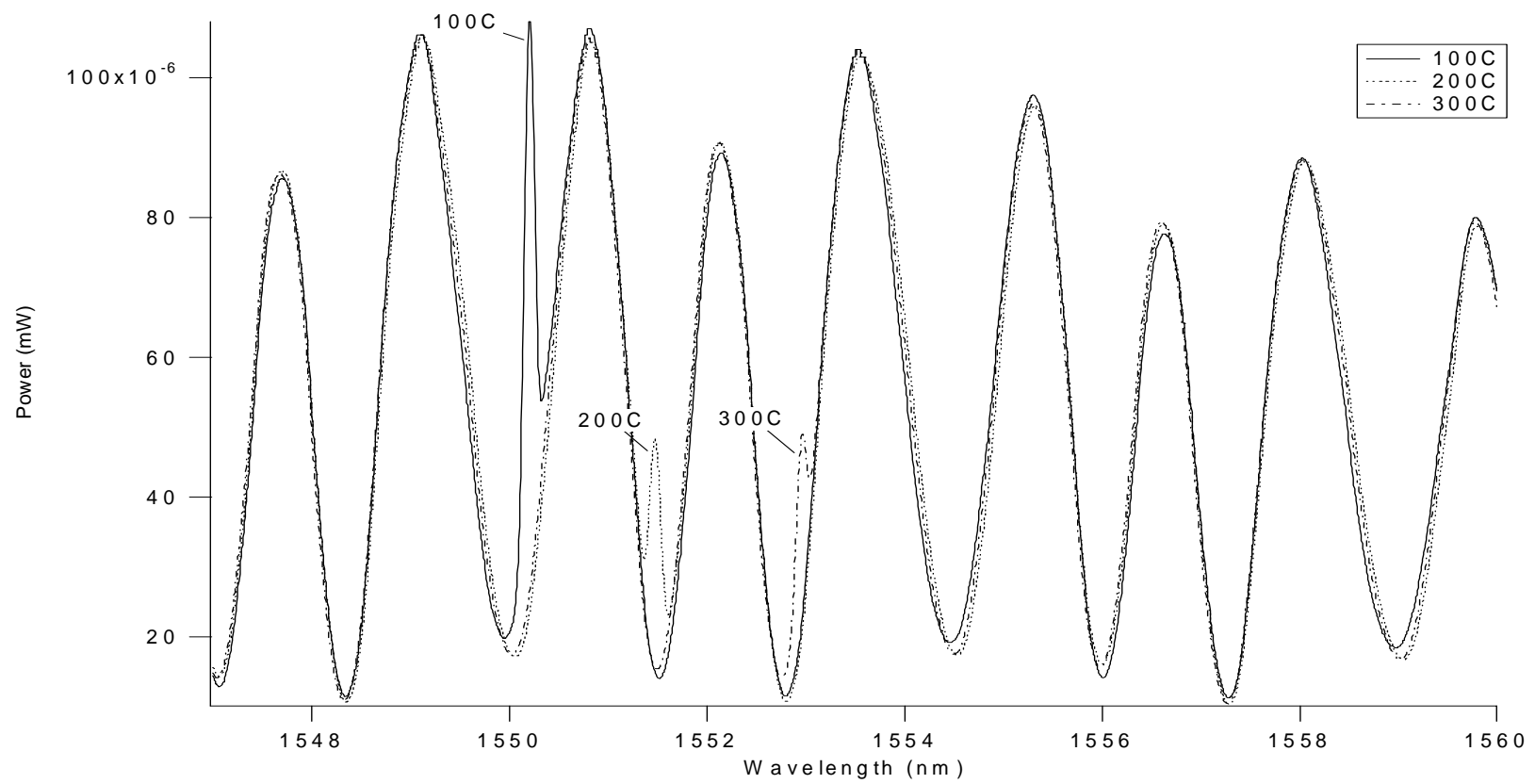

Fig. 5. Impact of an unbalanced interferometer on FBG spectra recorded by a spectrum analyzer at three different temperatures with the $100{ }^{\circ} \mathrm{C}$ interval in Fig. 4 


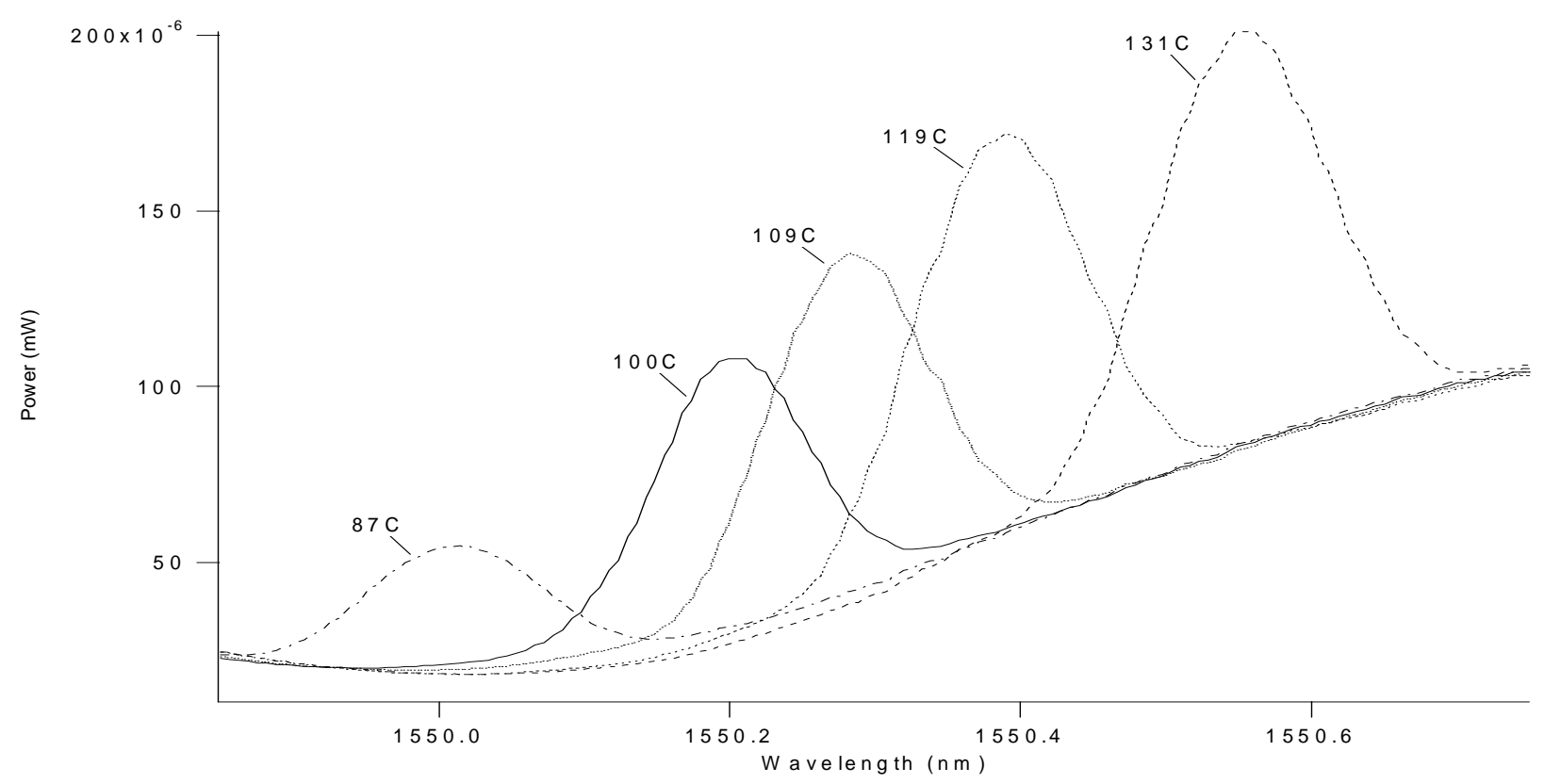

Fig. 6. FBG spectra obtained at five different temperatures that place the corresponding FBG wavelengths at a leading edge of the instrument function of the interferometer.

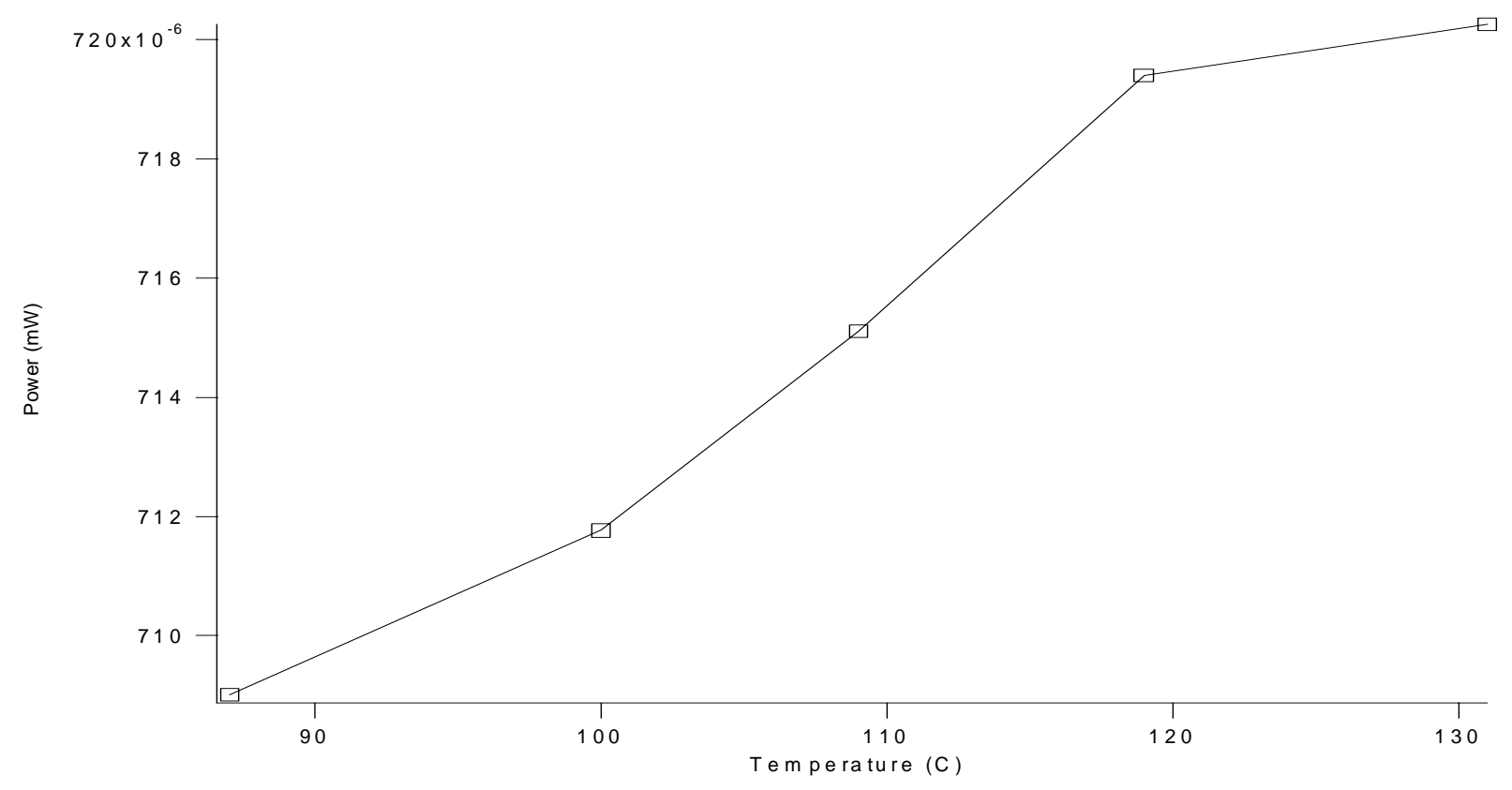

Fig. 7. Results of integration of the FBG spectra over a broad range of wavelengths, obtained at the five temperatures in Fig. 6. 
Public reporting burden for this collection of information is estimated to average 1 hour per response, including the time for reviewing instructions, searching existing data sources, gathering and maintaining the data needed, and completing and reviewing the collection of information. Send comments regarding this burden estimate or any other aspect of this collection of information, including suggestions for reducing this burden, to Washington Headquarters Services, Directorate for Information Operations and Reports, 1215 Jefferson Davis Highway, Suite 1204, Arlington, VA 22202-4302, and to the Office of Management and Budget, Paperwork Reduction Project (0704-0188), Washington, DC 20503.

\begin{tabular}{|l|l|l}
\hline 1. AGENCY USE ONLY (Leave blank) & $\begin{array}{c}\text { 2. REPORT DATE } \\
\text { March } 2005\end{array}$ & $\begin{array}{r}\text { 3. REPORT TYPE AND DATES COVERED } \\
\text { Technical Memorandum }\end{array}$ \\
\hline
\end{tabular}

4. TITLE AND SUBTITLE 5. FUNDING NUMBERS

Processing of Signals From Fiber Bragg Gratings Using Unbalanced Interferometers

6. AUTHOR(S)

WBS-22-066-30-03

Grigory Adamovsky, Jeff Juergens, and Bertram Floyd

7. PERFORMING ORGANIZATION NAME(S) AND ADDRESS(ES)

National Aeronautics and Space Administration

John H. Glenn Research Center at Lewis Field

Cleveland, Ohio 44135-3191

8. PERFORMING ORGANIZATION REPORT NUMBER

E-15062

9. SPONSORING/MONITORING AGENCY NAME(S) AND ADDRESS(ES)

10. SPONSORING/MONITORING AGENCY REPORT NUMBER

National Aeronautics and Space Administration

Washington, DC 20546-0001

NASA TM-2005-213594

\section{SUPPLEMENTARY NOTES}

Prepared for the International Symposia on Smart Structures and Materials/NDE sponsored by The International Society for Optical Engineering, San Diego, California, March 7-10, 2005. Grigory Adamovsky and Jeff Juergens, NASA Glenn Research Center; and Bertram Floyd, Akima Corporation, 22021 Brookpark Road, Fairview Park, Ohio 44126. Responsible person, Grigory Adamovsky, organization code RIO, e-mail: Grigory.Adamovsky-1@nasa.gov, 216-433-3736.

\begin{tabular}{l|l} 
12a. DISTRIBUTION/AVAILABILITY STATEMENT & 12b. DISTRIBUTION CODE
\end{tabular}

Unclassified - Unlimited

Subject Categories: 06, 19, and 35

Available electronically at http://gltrs.grc.nasa.gov

This publication is available from the NASA Center for AeroSpace Information, 301-621-0390.

13. ABSTRACT (Maximum 200 words)

Fiber Bragg gratings (FBG) have become preferred sensory structures in fiber optic sensing system. High sensitivity, embedability, and multiplexing capabilities make FBGs superior to other sensor configurations. The main feature of FBGs is that they respond in the wavelength domain with the wavelength of the returned signal as the indicator of the measured parameter. The wavelength is then converted to optical intensity by a photodetector to detect corresponding changes in intensity. This wavelength-to-intensity conversion is a crucial part in any FBG-based sensing system. Among the various types of wavelength-to-intensity converters, unbalanced interferometers are especially attractive because of their small weight and volume, lack of moving parts, easy integration, and good stability. In this paper we investigate the applicability of unbalanced interferometers to analyze signals reflected from Bragg gratings. Analytical and experimental data are presented.

\section{SUBJECT TERMS}

15. NUMBER OF PAGES

Fiber Bragg gratings; Temperature sensors; Fiber optics; Interferometer

14

Fiber Bragg gratings, Temperature sensors; Fiber optics, Interferometer

17. SECURITY CLASSIFICATION OF REPORT

Unclassified

18. SECURITY CLASSIFICATION
OF THIS PAGE
Unclassified

Unclassified

19. SECURITY CLASSIFICATION
OF ABSTRACT
Unclassified

Unclassified 

